\title{
Epigenetic regulation of the human telomerase reverse transciptase gene: A potential therapeutic target for the treatment of leukemia (Review)
}

\author{
XINBING SUI $^{1 *}$, NA KONG $^{1 *}$, ZHANGGUI WANG $^{1}$ and HONGMING PAN ${ }^{1,2}$ \\ ${ }^{1}$ Department of Medical Oncology, Sir Run Run Shaw Hospital, Zhejiang University; \\ ${ }^{2}$ Biomedical Research Center and Key Laboratory of Biotherapy, Hangzhou, Zhejiang 310016, P.R. China
}

Received January 15, 2013; Accepted May 17, 2013

DOI: $10.3892 / \mathrm{ol} .2013 .1367$

\begin{abstract}
Telomerase activation is a critical step in human carcinogenesis through the maintenance of telomeres. Telomerase activity is primarily regulated by the human telomerase reverse transcriptase gene ( $h T E R T)$, thus, an improved understanding of the transcriptional control of $h T E R T$ may provide potential therapeutic targets for the treatment of leukemia and other forms of cancer. Epigenetic modulation, a significant regulatory process in cell biology, has recently been shown to be involved in the regulation of the hTERT gene. Moreover, several epigenetic modifiers, including DNA methyltransferase (DNMT) and histone deacetylase (HDAC) inhibitors, are now in pre- and early clinical trials of leukemia as monotherapies or in combination with other drugs, and have achieved significant clinical success. In the present review, the epigenetic mechanisms associated with telomerase activity in leukemia, and the therapeutic potential of an antitelomerase strategy that combines epigenetic modifiers with telomerase hTR subunit small molecule inhibitors are discussed.
\end{abstract}

\section{Contents}

1. Introduction

2. Epigenetic regulation of $h T E R T$ and telomere length

3. Targeting telomerase ( $h T E R T)$ in leukemia cells through epigenetic modifiers presents new anticancer therapeutic approaches for leukemia

4. Future perspectives

Correspondence to: Professor Hongming Pan, Department of Medical Oncology, Sir Run Run Shaw Hospital, Zhejiang University, 3 East Qingchun Road, Hangzhou, Zhejiang 310016, P.R. China

E-mail:drpanhm@yahoo.com.cn

${ }^{*}$ Contributed equally

Key words: human telomerase reverse transcriptase, epigenetic, leukemia

\section{Introduction}

Telomeres serve as essential structures that protect the ends of linear chromosomes from DNA repair and degradation, and their maintenance is critical for long-term cell proliferation and survival $(1,2)$. Mammalian telomeres consist of tandem TTAGGG repeats that are bound by a specialized six-protein complex known as shelterin and may be replenished by telomerase (3). Telomerase is composed of two essential components, a catalytic subunit with reverse transcriptase activity, telomerase reverse transcriptase (TERT), and a telomerase RNA component (TERC), that acts as a template for DNA synthesis (4-6). Telomerase activity is overexpressed in the majority of cancer cells but is barely detectable in the predominance of normal somatic cells (7).

Among the various aspects of gene control, epigenetic alterations have gained attention as critical determinants for tumor initiation and subsequent cancer progression $(8,9)$. The forms of epigenetic control of gene expression include DNA methylation and histone modification. DNA methylation involves a covalent modification at the fifth carbon position of cytosine residues within $\mathrm{CpG}$ dinucleotides, resulting in the transcriptional silencing of the affiliated gene (10). Promoter hypermethylation of tumor suppressor genes has been increasingly considered as a fundamental mechanism for the silencing of these genes in cancer cells, resulting in tumor initiation and progression $(11,12)$. In addition to DNA methylation, another key element in the epigenetic control of gene expression is histone modification, including acetylation, methylation, phosphorylation and ubiquitination. Aberrant patterns of histone modifications have been associated with a large number of human malignancies $(13,14)$. DNA methylation and histone modifications have been extensively recognized as epigenetic mechanisms that regulate gene transcription in carcinogenesis.

Human (h)TERT, a catalytic subunit of telomerase, is a key determinant for the control of telomerase activity (15). The hTERT promoter contains two E-box regions and five GC boxes (16). Similar to numerous human genes, hTERT also contains a $\mathrm{CpG}$ island in its promoter region, indicating a role for methylation in the regulation of hTERT expression (17). Accumulating evidence indicates that hTERT contains an increased level of DNA methylation in its promoter region in 
A

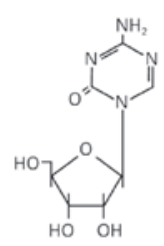

5-azacytidine (azacitidine)

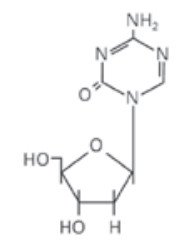

5-aza-2'-deoxycytidine (decitabine)
B

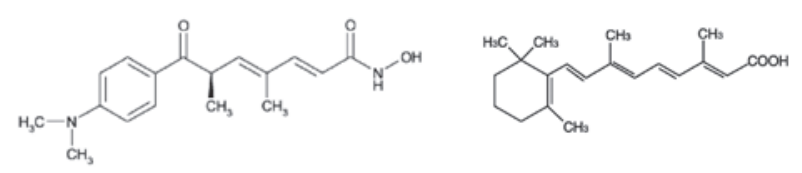

Trichostatin A (TSA)

all-trans retinoic acid (ATRA)

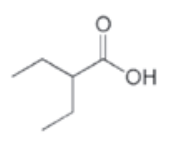

Valproic acid (VPA)

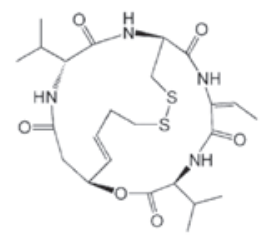

Depsipeptide (FK228)

Figure 1. Chemical structures of selected (A) DNMT inhibitors and (B) HDAC inhibitors. DNMT, DNA methyltransferase; HDAC, histone deactylase.

numerous cancers. Moreover, hTERT hypermethylation has been associated with the stable silencing of $h T E R T$ promoter expression $(18,19)$. Histone deacetylation/methylation has also been reported to be responsible for the repressive status of the $h T E R T$ promoter (20). In the present review, the contribution of the epigenetic dysregulation of $h T E R T$ expression to leukemogenesis, and the prospect of this regulation as a basis for developing new anticancer therapies for leukemia are discussed.

\section{Epigenetic regulation of $h T E R T$ and telomere length}

Telomere length, maintained by telomerase, is a prominent mechanism for long-term cell proliferation and survival, and is strongly involved in cancer, cell senescence and aging (21-23). It has been demonstrated that the epigenetic plasticity of the hTERT gene promoter is a determinant for the control of telomerase activity. Therefore, inhibiting the expression of the $h T E R T$ gene through epigenetic mechanisms usually results in telomeric attrition. The epigenetic changes associated with the inhibition of telomerase activity include hypermethylation and histone modifications of the $h T E R T$ promoter.

The proximal core promoter region of the $h T E R T$ gene harbors a high GC content and therefore, may be partly regulated by DNA methylation. Currently, there are three major DNA methyltransferases (DNMTs) identified to be responsible for the establishment of DNA methylation in the hTERT promoter (24). In the majority of cases, the aberrant methylation of $\mathrm{CpG}$ islands in promoter regions results in the heritable silencing of genes without a change in their coding sequence (25). Recent studies have shown that telomerase activity is repressed through the epigenetic silencing of $h T E R T$, which is accompanied by telomere shortening $(26,27)$. Shin et al reported that hypermethylation of the hTERT promoter played a critical role in the negative regulation of telomerase activity in normal human oral cells (27). Zinn et al also showed that the DNA methylation patterns of the hTERT promoter decreased $h T E R T$ transcription and telomerase activity, which was consistent with the normal paradigm of methylation-induced gene silencing (28). Paradoxically, there are conflicting studies with regard to the correlation between hypermethylation of the hTERT promoter, $h T E R T$ gene expression and telomerase activity. It is increasingly apparent that the $h T E R T$ promoter is partially or completely hypermethylated in telomerase-positive tumors, but unmethylated or hypomethylated in telomerase-negative normal tissues $(16,29)$. Treatment using 5-azacytidine (azacitidine) and its deoxy analogue 5-aza-2'-deoxycytidine (decitabine; DAC), two common demethylating agents, is able to cause a reduction in hTERT gene expression and consequently, telomerase activity (Fig. 1) (30-32). This correlation was in contrast with the general model of gene regulation by promoter methylation. Taken together, these studies indicate that hTERT may have an effect on telomerase activity through epigenetic regulation. However, the exact mechanism by which DNA methylation affects $h T E R T$ gene expression and telomerase activity remains to be elucidated (Fig. 2).

In addition to DNA methylation, another prevalent epigenetic mechanism that affects $h T E R T$ transcription is histone modification, including histone acetylation, methylation, phosphorylation and ubiquitinization. Histone tails carry basic charges and are associated with DNA molecules by electrostatic attraction. The acetylation of the histone proteins neutralizes the charge status of the histone tails, which decreases the attraction force between DNA and the histone tails, thus conferring an opened chromatin structure, allowing transcription factors, including c-MYC, MAD1 and CTCF, to bind to the DNA. Conversely, the deacetylation of histones results in the transcription factors having less access to the DNA $(33,34)$. It has been demonstrated that Trichostatin A (TSA), a histone deacetylase (HDAC) inhibitor, is able to induce $h T E R T$ transcription and telomerase activity in normal cells and telomerase-negative immortal cell lines through the inhibition of histone deacetylation (Fig. 1) (35,36). Furthermore, FR901288, a novel cyclic peptide inhibitor of HDAC, has also been shown to activate hTERT mRNA expression in oral cancer cell lines (37). However, there are conflicting studies with regard to $h T E R T$ transcription and telomerase activity in cancer cells induced by HDAC inhibitors. Zhu et al reported that HDAC inhibitors prevented cell proliferation and induced apoptosis, but had no effect on the expression of hTERC and hTERT mRNA, 
Table I. Selected drugs with epigenetic targets in the preclinical and clinical development of leukemia.

\begin{tabular}{llll}
\hline Drug target & Drug & Chemical class & Study in leukemia \\
\hline DNMT inhibitor & Azacitidine & Nucleoside analog & ALL, AML, CML \\
DNMT inhibitor & Decitabine (DAC) & Nucleoside analog & ALL, AML, CML \\
HDAC inhibitor & Valproic acid (VPA) & Short-chain fatty acid & AML, CLL, CML \\
HDAC inhibitor & Trichostatin A(TSA) & Hydroxamic acid & Preclinical trials \\
HDAC inhibitor & Panobinostat (LBH589) & Hydroxamic acid & ALL, AML \\
HDAC inhibitor & Depsipeptide (FR901228/FK228) & Cyclic tetrapeptide & AML \\
HDAC inhibitor & Entinostat (MS275/SNDX-275) & Benzamide & ALL, AML \\
HDAC inhibitor & MGCD0103 & Benzamide & AML, CLL \\
\hline
\end{tabular}

AML, acute myelogenous leukemia; ALL, acute lymphocytic leukemia; CLL, chronic lymphocytic leukemia; CML, chronic myelogenous leukemia. DNMT, DNA methyltransferase; HDAC, histone deactylase.

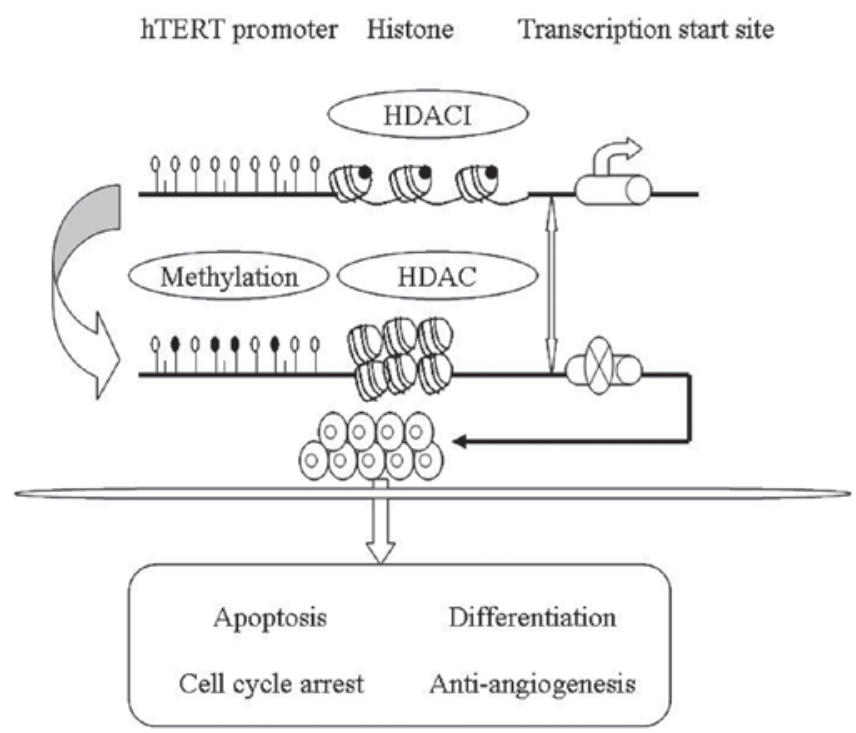

Figure 2. Complex molecular mechanisms and biological effects of $h T E R T$. Epigenetic modification may affect $h T E R T$ expression and will form a permissive or inhibitive condition for $h T E R T$ transcription, depending on the specific cellular context. The suppression of $h T E R T$ promotes growth inhibition, differentiation, apoptosis and anti-angiogenesis. hTERT, human telomerase reverse transcriptase; HDAC, histone deacetylase; HDACI, HDAC inhibitor.

or on telomerase activity (38). In prostate and brain cancer cells, the $h T E R T$ gene expression and telomerase activity were inhibited by HDAC inhibitors $(30,40)$. Therefore, the HDAC inhibitors may exhibit various effects on $h T E R T$ transcription and telomerase activity in cancer cells. In addition to histone acetylation, $h T E R T$ transcription was also reported to be associated with histone methylation, of which three varying forms, including mono-, di- and trimethylation, may emerge in methylation modifications of the histone lysine residues. It has been demonstrated that mono- and dimethylated histone3-lysine9 (H3-K9) are localized to distinct domains of silent chromatin, where they are associated with inactive genes, whereas trimethylated $\mathrm{H} 3-\mathrm{K} 9$ is enriched in pericentric heterochromatin (41). Further studies have shown that a lack of $h T E R T$ expression in telomerase-negative cell lines is associated with histone H3 and H4 hypoacetylation and the methylation of H3-K9. However, hTERT transcription in telomerase-positive cell lines is associated with the hyperacetylation of $\mathrm{H} 3$ and $\mathrm{H} 4$ and the methylation of Lys4-H3 (H3-K4) (42). Histone methyltransferase (HMTase) is considered to be responsible for histone methylation at the $h T E R T$ promoter. Liu et al reported that SET and MYND domain-containing protein 3 (SMYD3), a HMTase, may directly transactivate $h T E R T$ transcription and telomerase activity in normal human fibroblasts and cancer cell lines through histone H3-K4 trimethylation (43). These results suggest that the epigenetic regulation of histones may contribute to $h T E R T$ gene expression and telomerase activity (Fig. 2).

\section{Targeting telomerase ( $h T E R T)$ in leukemia cells through epigenetic modifiers presents new anticancer therapeutic approaches for leukemia}

Telomerase activity is a hallmark of the immortal cell phenotype and several mechanisms have been reported to be involved in its regulation, including transcriptional factors, DNA methylation and histone deacetylation. Furthermore, it has been shown that cells in numerous types of leukemia are able to maintain their telomere length and prevent replicative senescence or apoptosis by the epigenetic regulation of hTERT (44-46). Therefore, telomerase suppression using epigenetic modifications should be a promising target for the treatment of leukemia.

Studies have linked differentiation therapy to the epigenetic regulation of $h T E R T$, and a large number of demethylating agents and HDAC inhibitors have achieved significant clinical successes in inducing the differentiation of human leukemia cells (Table I). Low methylation levels of the hTERT promoter core domain have been shown to correlate with high telomerase activity in patients with B-cell chronic lymphocytic leukemia (B-CLL), whereas a high degree of methylation indicates low enzyme activity. Moreover, patients with a high level of telomerase activity show a worse prognosis $(47,48)$. Azacitidine and its deoxy analogue, decitabine, which are two DNMT inhibitors, have been approved as single agents to treat patients with leukemia through the induction of cell differentiation (Fig. 1) (49-52). 


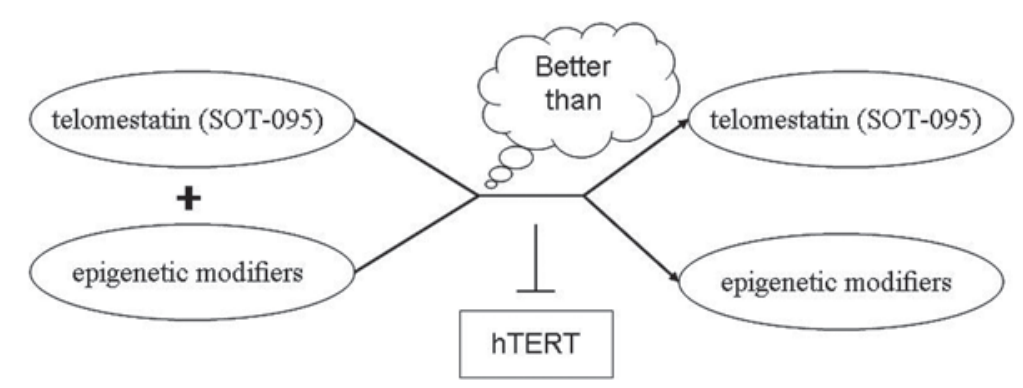

Figure 3. A hypothesis is associated with antitelomerase strategy. The antitelomerase strategy, created by combining epigenetic modifiers with telomerase hTR subunit small molecule inhibitors (such as SOT-095), may exert a more potent effect for the treatment of human leukemia, since each approach is able to individually inhibit telomerase activity. hTERT, human telomerase reverse transcriptase.

HDAC inhibitors are agents that have attracted interest due to their ability to induce the differentiation of leukemic cells, and are now in pre- and early clinical trials as monotherapies and in combination with other drugs $(53,54)$. Previous studies have shown that the transcriptional suppression of the $h T E R T$ gene during all-trans retinoic acid (ATRA) treatment is associated with the differentiation of leukemia cells, partly due to DNA methylation and histone deacetylation in the hTERT promoter region (47,55-56). Recently, it has been revealed that $h T E R T$ is downregulated 5-fold through epigenetic and protein acetylation mechanisms using a combined treatment of aurora kinase inhibitors (AKi) and HDAC inhibitors $(57,58)$. Azouz et al identified two distinct functional domains of the $h T E R T$ promoter, the proximal and distal domains, and identified that the epigenetic modifications of the distal region determined the retinoid capacity to repress telomerase in maturation-resistant acute promyelocytic leukemia cells during cellular differentiation (59). Love et al showed that epigenetic regulation stabilized hTERT inhibition and thus maintained telomerase activity in a silenced state during the ATRA-induced differentiation of HL60 human leukemia cells (60). Altogether, these data indicate that epigenetic mechanisms may represent a target for maintaining the differentiated phenotype of human leukemia cells.

In addition to inducing cell differentiation, telomerase inhibition through epigenetic mechanisms has been reported to promote growth arrest, apoptosis and sensitivity to certain chemotherapeutic reagents in human acute leukemia cells. Woo et al demonstrated that TSA had an antiproliferative and apoptosis-inducing effect on the human leukemic cell line U937, and that these growth-inhibitory effects were associated with the inhibition of hTERT expression and telomerase activity. Therefore, a loss of telomerase activity may be a good surrogate biomarker to assess the antitumor activity of TSA in human leukemic cells (61). The resistance to imatinib is a major problem in chronic myelogenous leukemia (CML) treatment, and recent studies have shown that by targeting telomerase expression using a dominant-negative form of the catalytic protein subunit of $h T E R T$, or by the treatment with HDAC inhibitors, the risk of imatinib resistance may be reduced and the imatinib-induced apoptosis in leukemia cells may be enhanced, suggesting that antitelomerase strategies may be able to prevent, or at least delay the onset of such resistance $(62,63)$.

\section{Future perspectives}

The hTERT gene is usually transcriptionally inactivated in differentiated cells, but is reactivated in the majority of leukemia cells. As previously discussed, accumulating evidence suggests that epigenetic changes in the hTERT promoter may be a prominent mechanism of telomerase activity control. Therefore, antitelomerase strategies using epigenetic mechanisms may represent a promising target for the treatment of leukemia. There are two major approaches in advanced clinical trials to target telomerase-positive leukemia cells. Firstly, the use of direct telomerase hTR subunit small molecule inhibitors, such as telomestatin (SOT-095), several of which are currently in preclinical trials for acute leukemia $(64,65)$. The second approach involves using epigenetic modification drugs against the hTERT protein; these drugs are currently being used for, or have completed trials for the treatment of leukemia. At present, there is an increasing interest in using epigenetic modifiers as candidate chemotherapeutic agents in human leukemia.

Epigenetic modifiers that are currently available in preclinical and early clinical trials of leukemia target DNMTs through DNMT inhibitors, or alter the status of the histones using HDAC inhibitors, in order to modulate gene transcription. It has been noted that epigenetic modifications contribute to $h T E R T$ gene expression and telomerase activity, resulting in a positive effect in the treatment of leukemia $(59,61)$. In addition to epigenetic modifiers, the use of several telomerase hTR subunit small molecule inhibitors has resulted in the specific inhibition of telomerase activity. Therefore, an antitelomerase strategy involving a combination of epigenetic modifiers and telomerase hTR subunit small molecule inhibitors may exert a more potent effect for the treatment of human leukemia (Fig. 3).

Although epigenetic modifiers have shown promise as therapies for human leukemia in early clinical trials, certain limitations prevent their widespread clinical application. Firstly, the exact molecular mechanisms underlying the epigenetic regulation and $h T E R T$ expression remain to be elucidated, as do numerous details with regard to telomerase regulation. An improved understanding of the linkage will facilitate the identification of more specific and selective epigenetic modifiers for leukemia cells (66). Secondly, a broad spectrum of biological and potentially adverse effects have been identified following treatment using epigenetic modifiers. Further investigation with regard to these effects 
is required in large-scale and multicentric populations of treated patients (67). Thirdly, further studies will be required to identify whether the inhibition of $h T E R T$ gene expression is causal or consequential to the anticancer effects of epigenetic modifiers, and whether the $h T E R T$ gene or telomerase activity may be an appropriate predictive biomarker for assessing the antitumor activity of these agents in human leukemia cells (68). Finally, it should be taken into account whether the antitelomerase approach using epigenetic modifiers with telomerase hTR subunit small molecule inhibitors may be a better combinatorial strategy when compared with methods that are already used in prospective clinical trials.

Despite the unanswered biological questions, an increased understanding of the role of epigenetic regulation in $h T E R T$ gene expression and the treatment of leukemia may provide a prospective anticancer therapeutic approach in the form of the antitelomerase strategy.

\section{Acknowledgements}

This study is supported by Zhejiang University and grants from the National Natural Science Foundation of China (grant no. 81272593) and the Zhejiang Provincial Natural Science Foundation of China (grant no. LQ13H160008).

\section{References}

1. de Lange T: Shelterin: the protein complex that shapes and safeguards human telomeres. Genes Dev 19: 2100-2110, 2005.

2. Palm $\mathrm{W}$ and de Lange $\mathrm{T}$ : How shelterin protects mammalian telomeres. Annu Rev Genet 42: 301-334, 2008.

3. Morin GB: The human telomere terminal transferase enzyme is a ribonucleoprotein that synthesizes TTAGGG repeats. Cell 59: 521-529, 1989.

4. Cohen SB, Graham ME, Lovrecz GO, Bache N, Robinson PJ and Reddel RR: Protein composition of catalytically active human telomerase from immortal cells. Science 315 1850-1853, 2007.

5. Blackburn EH: Switching and signaling at the telomere. Cell 106: 661-673, 2001

6. Pinto AR, Li H, Nicholls C and Liu JP: Telomere protein complexes and interactions with telomerase in telomere maintenance. Front Biosci 16: 187-207, 2011.

7. Kim NW, Piatyszek MA, Prowse KR, Harley CB, West MD Ho PL, Coviello GM, Wright WE, Weinrich SL and Shay JW: Specific association of human telomerase activity with immortal cells and cancer. Science 266: 2011-2015, 1994.

8. Agrelo R and Wutz A: Cancer progenitors and epigenetic contexts: an Xisting connection. Epigenetics 4: 568-570, 2009.

9. Vineis $\mathrm{P}$, Chuang SC, Vaissière T, Cuenin C, Ricceri F; Genair-EPIC Collaborators, Johansson M, Ueland P, Brennan P and Herceg Z: DNA methylation changes associated with cancer risk factors and blood levels of vitamin metabolites in a prospective study. Epigenetics 6: 195-201, 2011.

10. Laird PW: The power and the promise of DNA methylation markers. Nat Rev Cancer 3: 253-266, 2003.

11. Baylin SB and Ohm JE: Epigenetic gene silencing in cancer - a mechanism for early oncogenic pathway addiction? Nat Rev Cancer 6: 107-116, 2006.

12. Shao C, Lacey M, Dubeau L and Ehrlich M: Hemimethylation footprints of DNA demethylation in cancer. Epigenetics 4: $165-175,2009$

13. Sawan $C$ and Herceg $\mathrm{Z}$ : Histone modifications and cancer. Adv Genet 70: 57-85, 2010.

14. Rivière G, Lienhard D, Andrieu T, Vieau D, Frey BM and Frey FJ: Epigenetic regulation of somatic angiotensin-converting enzyme by DNA methylation and histone acetylation. Epigenetics 6: 478-489, 2011.

15. Cairney CJ and Keith WN: Telomerase redefined: integrated regulation of hTR and hTERT for telomere maintenance and telomerase activity. Biochimie 90: 13-23, 2008.
16. Dessain SK, Yu H, Reddel RR, Beijersbergen RL and Weinberg RA: Methylation of the human telomerase gene $\mathrm{CpG}$ island. Cancer Res 60: 537-541, 2000.

17. Zhu J, Zhao Y and Wang S: Chromatin and epigenetic regulation of the telomerase reverse transcriptase gene. Protein Cell 1: 22-32, 2010.

18. Iliopoulos D, Oikonomou P, Messinis I and Tsezou A: Correlation of promoter hypermethylation in hTERT, DAPK and MGMT genes with cervical oncogenesis progression. Oncol Rep 22: 199-204, 2009.

19. Gigek CO, Leal MF, Silva PN, Lisboa LC, Lima EM, Calcagno DQ, Assumpção PP, Burbano RR and Smith Mde A: hTERT methylation and expression in gastric cancer. Biomarkers 14: 630-636, 2009.

20. Wang $\mathrm{S}, \mathrm{Hu} \mathrm{C}$ and $\mathrm{Zhu} \mathrm{J}$ : Distinct and temporal roles of nucleosomal remodeling and histone deacetylation in the repression of the hTERT gene. Mol Biol Cell 21: 821-832, 2010.

21. Jia W, Wang S, Horner JW, Wang N, Wang H, Gunther EJ, DePinho RA and Zhu J: A BAC transgenic reporter recapitulates in vivo regulation of human telomerase reverse transcriptase in development and tumorigenesis. FASEB J 25: 979-989, 2011.

22. Baird DM, Rowson J, Wynford-Thomas D and Kipling D: Extensive allelic variation and ultrashort telomeres in senescent human cells. Nat Genet 33: 203-207, 2003.

23. Harley CB, Futcher AB and Greider CW: Telomeres shorten during ageing of human fibroblasts. Nature 345: 458-460, 1990.

24. Li Y, Liu L, Andrews LG and Tollefsbol TO: Genistein depletes telomerase activity through cross-talk between genetic and epigenetic mechanisms. Int J Cancer 125: 286-296, 2009.

25. Egger G, Liang G, Aparicio A and Jones PA: Epigenetics in human disease and prospects for epigenetic therapy. Nature 429: 457-463, 2004.

26. Lopatina NG, Poole JC, Saldanha SN, Hansen NJ, Key JS, Pita MA, Andrews LG and Tollefsbol TO: Control mechanisms in the regulation of telomerase reverse transcriptase expression in differentiating human teratocarcinoma cells. Biochem Biophys Res Commun 306: 650-659, 2003.

27. Shin KH, Kang MK, Dicterow E and Park NH: Hypermethylation of the hTERT promoter inhibits the expression of telomerase activity in normal oral fibroblasts and senescent normal oral keratinocytes. Br J Cancer 89: 1473-1478, 2003.

28. Zinn RL, Pruitt K, Eguchi S, Baylin SB and Herman JG: hTERT is expressed in cancer cell lines despite promoter DNA methylation by preservation of unmethylated DNA and active chromatin around the transcription start site. Cancer Res 67: 194-201, 2007.

29. Devereux TR, Horikawa I, Anna CH, Annab LA, Afshari CA and Barrett JC: DNA methylation analysis of the promoter region of the human telomerase reverse transcriptase (hTERT) gene. Cancer Res 59: 6087-6090, 1999.

30. Kumari A, Srinivasan R, Vasishta RK and Wig JD: Positive regulation of human telomerase reverse transcriptase gene expression and telomerase activity by DNA methylation in pancreatic cancer. Ann Surg Oncol 16: 1051-1059, 2009.

31. Kumari A, Srinivasan R and Wig JD: Effect of c-MYC and E2F1 gene silencing and of 5-azacytidine treatment on telomerase activity in pancreatic cancer-derived cell lines. Pancreatology 9: 360-368 2009.

32. Guilleret I, Yan P, Grange F, Braunschweig R, Bosman FT and Benhattar J: Hypermethylation of the human telomerase catalytic subunit (hTERT) gene correlates with telomerase activity. Int J Cancer 101: 335-341, 2002.

33. Krajewski WA: Histone acetylation status and DNA sequence modulate ATP-dependent nucleosome repositioning. J Biol Chem 277: 14509-14513, 2002.

34. Lai SR, Phipps SM, Liu L, Andrews LG and Tollefsbol TO: Epigenetic control of telomerase and modes of telomere maintenance in aging and abnormal systems. Front Biosci 10: 1779-1796, 2005.

35. Takakura M, Kyo S, Sowa Y, Wang Z, Yatabe N, Maida Y, Tanaka $\mathbf{M}$ and Inoue $M$ : Telomerase activation by histone deacetylase inhibitor in normal cells. Nucleic Acids Res 29: 3006-3011, 2001

36. Hou M, Wang X, Popov N, Zhang A, Zhao X, Zhou R, Zetterberg A, Björkholm M, Henriksson M, Gruber A and Xu D: The histone deacetylase inhibitor trichostatin A derepresses the telomerase reverse transcriptase (hTERT) gene in human cells. Exp Cell Res 274: 25-34, 2002. 
37. Murakami J, Asaumi J, Kawai N, Tsujigiwa H, Yanagi Y, Nagatsuka H, Inoue T, Kokeguchi S, Kawasaki S, Kuroda M, Tanaka N,Matsubara N and Kishi K:Effects of histone deacetylase inhibitor FR901228 on the expression level of telomerase reverse transcriptase in oral cancer. Cancer Chemother Pharmacol 56: 22-28, 2005.

38. Zhu K, Qu D, Sakamoto T, Fukasawa I, Hayashi M and Inaba N: Telomerase expression and cell proliferation in ovarian cancer cells induced by histone deacetylase inhibitors. Arch Gynecol Obstet 277: 15-19, 2008.

39. Suenaga M, Soda H, Oka M, Yamaguchi A, Nakatomi K, Shiozawa K, Kawabata S, Kasai T, Yamada Y, Kamihira S, Tei C and Kohno S: Histone deacetylase inhibitors suppress telomerase reverse transcriptase mRNA expression in prostate cancer cells. Int J Cancer 97: 621-625, 2002.

40. Khaw AK, Silasudjana M, Banerjee B, Suzuki M, Baskar R and Hande MP: Inhibition of telomerase activity and human telomerase reverse transcriptase gene expression by histone deacetylase inhibitor in human brain cancer cells. Mutat Res 625: 134-144, 2007.

41. Rice JC, Briggs SD, Ueberheide B, Barber CM, Shabanowitz J, Hunt DF, Shinkai Y and Allis CD: Histone methyltransferases direct different degrees of methylation to define distinct chromatin domains. Mol Cell 12: 1591-1598, 2003.

42. Atkinson SP, Hoare SF, Glasspool RM and Keith WN: Lack of telomerase gene expression in alternative lengthening of telomere cells is associated with chromatin remodeling of the hTR and hTERT gene promoters. Cancer Res 65: 7585-7590, 2005.

43. Liu C, Fang X, Ge Z, Jalink M, Kyo S, Björkholm M, Gruber A, Sjöberg $\mathrm{J}$ and $\mathrm{Xu} \mathrm{D}$ : The telomerase reverse transcriptase (hTERT) gene is a direct target of the histone methyltransferase SMYD3. Cancer Res 67: 2626-26, 2007.

44. Röth A, Vercauteren S, Sutherland HJ and Lansdorp PM: Telomerase is limiting the growth of acute myeloid leukemia cells. Leukemia 17: 2410-2417, 2003.

45. Annaloro C, Onida F, Saporiti G and Lambertenghi Deliliers G: Cancer stem cells in hematological disorders: current and possible new therapeutic approaches. Curr Pharm Biotechnol 12: 217-225, 2011

46. Liu L, Saldanha SN, Pate MS, Andrews LG and Tollefsbol TO: Epigenetic regulation of human telomerase reverse transcriptase promoter activity during cellular differentiation. Genes Chromosomes Cancer 41: 26-37, 2004.

47. Bechter OE, Eisterer W, Dlaska M, Kühr T and Thaler J: CpG island methylation of the hTERT promoter is associated with lower telomerase activity in B-cell lymphocytic leukemia. Exp Hematol 30: 26-33, 2002

48. Terrin L, Trentin L, Degan M, Corradini I, Bertorelle R, Carli P, Maschio N, Bo MD, Noventa F, Gattei V, Semenzato G and De Rossi A: Telomerase expression in B-cell chronic lymphocytic leukemia predicts survival and delineates subgroups of patients with the same igVH mutation status and different outcome. Leukemia 21: 965-972, 2007.

49. LübbertM,Suciu S,BailaL,RüterBH,PlatzbeckerU,Giagounidis A, Selleslag D, Labar B, Germing U, Salih HR, Beeldens F, Muus P, Pflüger KH, Coens C, Hagemeijer A, Eckart Schaefer H, Ganser A, Aul C, de Witte T and Wijermans PW: Low-dose decitabine versus best supportive care in elderly patients with intermediateor high-risk myelodysplastic syndrome (MDS) ineligible for intensive chemotherapy: final results of the randomized phase III study of the European Organisation for Research and Treatment of Cancer Leukemia Group and the German MDS Study Group. J Clin Oncol 29: 1987-1996, 2011.

50. Kantarjian HM, Giles FJ, Greenberg PL, Paquette RL, Wang ES, Gabrilove JL, Garcia-Manero G, Hu K, Franklin JL and Berger DP: Phase 2 study of romiplostim in patients with low- or intermediate-risk myelodysplastic syndrome receiving azacitidine therapy. Blood 116: 3163-3170, 2010.
51. Baer MR and Gojo I: Novel agents for the treatment of acute myeloid leukemia in the older patient. J Natl Compr Canc Netw 9: 331-335, 2011

52. Garcia-Manero G, Gore SD, Cogle C, Ward R, Shi T, Macbeth KJ, Laille E, Giordano H, Sakoian S, Jabbour E, Kantarjian H and Skikne B: Phase I study of oral azacitidine in myelodysplastic syndromes, chronic myelomonocytic leukemia, and acute myeloid leukemia. J Clin Oncol 29: 2521-2527, 2011.

53. Claus R and Lübbert M: Epigenetic targets in hematopoietic malignancies. Oncogene 22: 6489-6496, 2003.

54. Lane AA and Chabner BA: Histone deacetylase inhibitors in cancer therapy. J Clin Oncol 27: 5459-5468, 2009.

55. Pendino F, Sahraoui T, Lanotte M and Ségal-Bendirdjian E: A novel mechanism of retinoic acid resistance in acute promyelocytic leukemia cells through a defective pathway in telomerase regulation. Leukemia 16: 826-832, 2002.

56. Pendino F, Flexor M, Delhommeau F, Buet D, Lanotte M and Segal-Bendirdjian E: Retinoids down-regulate telomerase and telomere length in a pathway distinct from leukemia cell differentiation. Proc Natl Acad Sci USA 98: 6662-6667, 2001.

57. Kretzner L, Scuto A, Dino PM, Kowolik CM, Wu J, Ventura P, Jove R, Forman SJ, Yen Y and Kirschbaum MH: Combining histone deacetylase inhibitor vorinostat with aurora kinase inhibitors enhances lymphoma cell killing with repression of c-Myc, hTERT, and microRNA levels. Cancer Res 71: 3912-3920, 2011.

58. Quintás-Cardama A, Santos FP and Garcia-Manero G: Histone deacetylase inhibitors for the treatment of myelodysplastic syndrome and acute myeloid leukemia. Leukemia 25: 226-235, 2011.

59. Azouz A, Wu YL, Hillion J, Tarkanyi I, Karniguian A, Aradi J, Lanotte M, Chen GQ, Chehna M and Ségal-Bendirdjian E: Epigenetic plasticity of hTERT gene promoter determines retinoid capacity to repress telomerase in maturation-resistant acute promyelocytic leukemia cells. Leukemia 24: 613-622, 2010

60. Love WK, Berletch JB, Andrews LG and Tollefsbol TO: Epigenetic regulation of telomerase in retinoid-induced differentiation of human leukemia cells. Int J Oncol 32: 625-631, 2008.

61. Woo HJ, Lee SJ, Choi BT, Park YM and Choi YH: Induction of apoptosis and inhibition of telomerase activity by trichostatin A, a histone deacetylase inhibitor, in human leukemic U937 cells. Exp Mol Pathol 82: 77-84, 2007.

62. Okabe S, Tauchi T, Nakajima A, Sashida G, Gotoh A, Broxmeyer HE, Ohyashiki JH and Ohyashiki K: Depsipeptide (FK228) preferentially induces apoptosis in BCR/ABL-expressing cell lines and cells from patients with chronic myelogenous leukemia in blast crisis. Stem Cells Dev 16: 503-514, 2007.

63. Deville L, Hillion J, Pendino F, Samy M, Nguyen E and Ségal-Bendirdjian E: hTERT promotes imatinib resistance in chronic myeloid leukemia cells: therapeutic implications. Mol Cancer Ther 10: 711-719, 2011.

64. Nakajima A, Tauchi T, Sashida G, Sumi M, Abe K, Yamamoto K, Ohyashiki JH and Ohyashiki K: Telomerase inhibition enhances apoptosis in human acute leukemia cells: possibility of antitelomerase therapy. Leukemia 17: 560-567, 2003.

65. Tauchi T, Shin-ya K, Sashida G, Sumi M, Okabe S, Ohyashiki JH and Ohyashiki K: Telomerase inhibition with a novel G-quadruplex-interactive agent, telomestatin: in vitro and in vivo studies in acute leukemia. Oncogene 25: 5719-5725, 2006.

66. Altucci L, Clarke N, Nebbioso A, Scognamiglio A and Gronemeyer H: Acute myeloid leukemia: therapeutic impact of epigenetic drugs. Int J Biochem Cell Biol 37: 1752-1762, 2005.

67. Bhalla KN: Epigenetic and chromatin modifiers as targeted therapy of hematologic malignancies. J Clin Oncol 23: 3971-3993, 2005.

68. Piekarz RL and Bates SE: Epigenetic modifiers: basic understanding and clinical development. Clin Cancer Res 15: 3918-3926, 2009. 